\title{
Avaliação Microestrutural e Resistência à Corrosão de uma Junta Dissimilar entre um Aço de Alta Resistência e Baixa Liga e Aço um Inoxidável Duplex
}

\author{
Gulliver Catão Silva ${ }^{1}$ (D), José Adilson de Castro ${ }^{1}$ (D) , Lecino Caldeira² (D), Moisés Luiz Lagares Junior ${ }^{3}$ (iD \\ ${ }^{1}$ Universidade Federal Fluminense - UFF, Programa de Pós-graduação em Engenharia Mecânica, Volta Redonda, RJ, Brasil. \\ ${ }^{2}$ Instituto Federal de Educação, Ciência e Tecnologia do Sudeste de Minas Gerais - IF Sudeste MG-JF, Núcleo de Metalurgia, Juiz de Fora, MG, Brasil. \\ 3 Universidade Federal de Juiz de Fora - UFJF, Departamento de Engenharia de Produção e Mecânica, Juiz de Fora, MG, Brasil.
}

Como citar: Silva GC, Castro JA, Caldeira L, Lagares Junior MLL. Avaliação microestrutural e resistência à corrosão de uma junta dissimilar entre um aço de alta resistência e baixa liga e aço um inoxidável duplex. Soldagem \& Inspeção. 2019;v24:e2404. https://doi.org/10.1590/0104-9224/SI24.04

\begin{abstract}
Resumo: A união entre materiais dissimilares tem sido amplamente aplicada na indústria de petróleo e gás. Em geral, este tipo de soldagem é mais sensível às diferenças de composição química existente entre os metais envolvidos. Diante dessa perspectiva, este trabalho tem por objetivo avaliar, por união autógena, a microestrutura de uma junta soldada entre um aço de alta resistência e baixa liga da classe API 5 L X80 e um aço inoxidável duplex UNS S32304. Além disso, estudou-se o comportamento quanto à resistência à corrosão em uma solução simuladora de água do mar. A microestrutura e composição da junta soldada foram avaliadas por microscopia ótica e eletrônica, espectrometria de energia dispersiva (EDS). A resistência à corrosão foi estudada por polarização potenciodinâmica anódica e por ensaios de espectroscopia de impedância eletroquímica. As juntas soldadas apresentaram uma microestrutura que se difere em morfologia de ambos os metais de base, além disso, notou-se a migração de cromo e níquel do duplex para esta região que apresentou uma resistência à corrosão ligeiramente superior ao API. Desta forma, podemos concluir que as propriedades da junta dissimilar são compatíveis com as aplicações, sendo possível sua utilização usufruindo-se das vantagens da soldagem dissimilar.
\end{abstract}

Palavras-chave: Soldagem; Dissimilar; API; Duplex.

\section{Microstructural Evaluation and Corrosion Resistance of a Dissimilar Joint between a High Strength Low Alloy Steel and a Duplex Stainless Steel}

\begin{abstract}
The union between two dissimilar materials has been widely applied in the oil and gas industry. In general, this type of welding is more sensitive to differences in chemical composition between the metals involved. From this perspective, this work aims, by autogenous welding, to evaluate the microstructure of a joint welded between a high strength and low alloy steel of class API $5 \mathrm{~L}$ X80 and a duplex stainless steel UNS UNS S32304. Furthermore, the corrosion resistance of the dissimilar welding region was evaluated in a solution which simulates the seawater environment. The microstructural properties and composition of the welding region were studied using optical microscopy, scanning electronic microscopy (SEM) with energy dispersive spectroscopy (EDS). The corrosion resistance was studied by anodic potentiodynamic polarization and by electrochemical impedance spectroscopy. The dissimilar region differs from both materials in their microstructural characteristics and presented significant migration of chromium and nickel from duplex materials to the dissimilar region, which enhanced their corrosion resistance compared with the API. Therefore, we concluded that the dissimilar regions are compatible with the applications which allow taking the advantage of join these two materials.
\end{abstract}

Key-words: Welding; Dissimilar; API; Duplex.

\section{Introdução}

A união de materiais dissimilares é uma técnica de soldagem que tem sido amplamente utilizada na indústria de petróleo e gás sempre que uma transição de propriedades ou desempenho em serviço é requerida devido aos benefícios econômicos, bem como das vantagens decorrente da combinação de dois metais diferentes que permitem associar o melhor de cada um dos materiais envolvidos [1]. De modo geral, este tipo de soldagem é mais desafiador do que a união tradicional de materiais que 
possuem composição química ou comportamento semelhante, dado que, esse tipo de junção, é mais sensível às diferenças nas composições químicas, propriedades físicas e mecânicas dos metais de base [2].

A soldagem dissimilar é particularmente aplicada na união entre diferentes tipos de aços inoxidáveis e entre aços inoxidáveis e aços de alta resistência e baixa liga, que são largamente utilizados em vasos de pressão, caldeiras, trocadores de calor e em tubulações de plantas petroquímicas [3,4]. Estudos realizados por Wang et al. [5] na caracterização de juntas soldadas entre um aço inoxidável duplex SAF 2205 e um aço de alta resitencia e baixa liga (16MnR) mostraram que as diferenças existentes entre os materiais podem ampliar fenômenos de corrosão devido as microestruturas formadas na zona fundida.

Os aços alta resistência e baixa liga são utilizados na construção de oleodutos e gasodutos nos quais possuem excelente resistência mecânica e eficiência de transmissão tornando possível a operação em altas pressões de trabalho. O processo de soldagem a gás inerte GTAW (Gas Tungsten Arc Welding) tem sido utilizado neste tipo de tubulação especialmente naqueles que lidam com aplicações estruturais e de transporte. Uma aplicação dos aços de alta resistência e baixa liga da classe API (aços para tubos utilizados no transporte de óleo e gás de acordo com as especificações da norma API $5 \mathrm{~L}$ do American Petroleum Institute) está no transporte e exploração de hidrocarbonetos pelos chamados "Risers" (aços tubulares de alta resistência). Este tipo de tubulação na chamada "splash zone" (região localizada três metros acima e três metros abaixo do nível do mar) está mais suscetível a problemas de corrosão devido aos ciclos de umedecimento e secagem decorrentes do movimento da maré. Uma possível solução para amenizar este problema além de proteção catódica ou manutenção corretiva seria a substituição, apenas na "splash zone" por um aço inoxidável que possua boa resistência à corrosão [6].

Os aços inoxidáveis são amplamente utilizados na indústria de papel e celulose, petróleo e gás, petroquímica devido à conhecida resistência à corrosão, associada a excelente resistência mecânica. Esse tipo de aço é classificado em subgrupos conforme sua microestrutura: aços inoxidáveis ferríticos, martensíticos, austeníticos, endurecíveis por precipitação, duplex e super duplex. Segundo Tasalloti et al. [7] há uma demanda por substituir ligas com altos teores de Níquel por ligas metálicas que possuem menores concentrações deste elemento, sem que haja perdas significativas das suas principais propriedades (resistência mecânica e à corrosão). Diante da necessidade de materiais resistentes à corrosão com menores custos de fabricação surgiram os aços inoxidáveis duplex. Em geral, este tipo de aço inoxidável, possui maior resistência mecânica que os austeníticos e maior dureza que ferríticos, além disso, apresentam boa soldabilidade e alta resistência à corrosão sobtensão [8]. Esses aços apresentam uma microestrutura formada por ilhas brancas de austenita envolvidas por uma matriz de ferrita delta cuja fração volumétrica da austenita é da ordem de 0,55.

Contudo, a produção de um cordão de solda a partir da união de materiais diferentes, não é trivial. Devem-se compreender as relações dos vários de parâmetros de entrada controláveis, como tensão, corrente e velocidade de soldagem, bem como a interação existente entre eles compondo assim a energia de soldagem que são responsáveis pelas características finais de um cordão de solda. Vashishtha et al. [9], estudaram os efeitos de diferentes processos de soldagem nas propriedades microestruturais e mecânicas em uma junta formada por aços inoxidáveis austeníticos (304) e aços inoxidáveis austeníticos com alto teor de nitrogênio. Devendranath Ramkumar et al. [10], investigaram a relação estrutura-propriedade na soldagem entre os aços inoxidáveis super duplex e austenítico mediante a modificações nas variáveis de entrada do processo. Moteshakker et al. [11] avaliaram a microestrutura e resistência da junta dissimilar entre o aço inoxidável duplex UNS S32205 e o austenítico 316L decorrentes do processo de soldagem a arco GTAW, utilizando diferentes tipos de metais de adição.

Além disso, o estudo isolado da corrente, tensão e velocidade de soldagem têm sido relacionados à geometria do cordão, enquanto que o estudo da energia de soldagem exerce uma maior influência nas propriedades mecânicas e metalúrgicas finais da solda [12-14]. Assim, dado a possibilidade de união entre dois materiais dissimilares, qual será o efeito na geometria da junta soldada devido a uma variação na energia de soldagem? Além disso, para um mesmo valor de energia, os cordões de solda formados por diferentes combinações entre corrente, tensão, e velocidade de soldagem apresentarão microestruturas semelhantes?

Portanto, o objetivo deste trabalho é a caracterização da junta soldada entre um aço inoxidável duplex UNS S32304 e um aço de alta resistência e baixa liga da classe API $5 \mathrm{~L} \mathrm{X80} \mathrm{a} \mathrm{fim} \mathrm{de} \mathrm{resolver} \mathrm{problemas} \mathrm{de} \mathrm{corrosão} \mathrm{em} \mathrm{zonas} \mathrm{que} \mathrm{demandam}$ transição de propriedades. Além disso, este trabalho irá contribuir em termos de controle do processo através do estudo do efeito de uma variação na energia de soldagem capaz de responder a estes questionamentos.

\section{Materiais e Métodos}

Neste trabalho, utilizou-se o processo GTAW sem metal de adição com eletrodo de tungstênio torinado de fabricação nacional. Todas as soldas foram automatizadas na posição plana e realizadas com o auxílio de um sistema de posicionamento e deslocamento automático da tocha de soldagem mantendo-se um ângulo de inclinação de $90^{\circ}$ perpendicular à interface que une as chapas de aço inoxidável duplex UNS S32304 e API $5 \mathrm{~L}$ X80 (130 mm x $45 \mathrm{~mm}$ x 4 mm). A Tabela 1 apresenta composição química (\% em massa) dos metais de base utilizados. Os cordões de solda foram produzidos pelo arco elétrico gerado entre a interface que une os dois materiais e o eletrodo de tungstênio. Foi utilizada uma fonte de soldagem operando no modo corrente constante com a polaridade do eletrodo negativa. A vazão do gás ( $75 \%$ Ar- $25 \% \mathrm{CO}_{2}$ ) manteve-se constante para todos os níveis de energia de soldagem em $15 \mathrm{~L} / \mathrm{min}$. A distância entre o eletrodo e a junta a ser soldada foi da ordem de 1,5 mm para a soldagem autógena. 
Tabela 1. Composição Química (\% em massa) dos metais de base.

\begin{tabular}{cccccccccc}
\hline Classe & $\mathbf{C}$ & Mn & Si & P & V & Nb & Cr & Ni & Mo \\
UNS S32304 & 0,0193 & 1,53 & 0,32 & 0,024 & 0,049 & 0,004 & 22,25 & 3,80 & 0,25 \\
API 5L X80 & 0,061 & 1,77 & 0,10 & 0,00 & 0,020 & 0,060 & 0,19 & 0,02 & 0,22 \\
\hline
\end{tabular}

A cada teste de soldagem, variou-se a velocidade de soldagem e a corrente em dois níveis totalizando 4 condições distintas avaliadas. Os valores instantâneos de corrente, tensão, e vazão do gás foram obtidos através do sistema de aquisição de dados coletados a cada 0,5 ms fornecendo uma quantidade de pontos suficientes para obtenção das médias de I e $U$ para cada ensaio, possibilitando o cálculo da energia de soldagem real.

Para avaliação da geometria do cordão de solda e fração volumétrica dos microconstituintes na zona fundida (contribuição em termos de controle do processo), através do estudo do efeito de uma variação de corrente e velocidade de soldagem e consequentemente de energia de soldagem fornecida, a fim de responder as perguntas do capitulo anterior deste trabalho, foi adotada a ferramenta estatística "Design of Experiments" (DOE) ou "Planejamento Experimental Fatorial", do tipo $2^{2}$, com uma repetição e intercalação dos dados de entrada.

As respostas do processo (penetração, largura, área, fração volumétrica dos microconstituintes) são fortemente influenciadas pelas variáveis de entrada (corrente, tensão e velocidade de soldagem) de modo que a energia de soldagem atua como uma variável aglutinadora. Assim, os fatores de entrada serão a corrente de soldagem e a velocidade de soldagem ambos em dois níveis diferentes (baixo "_" e alto "+"). Neste trabalho, os valores nominais de entrada de corrente serão $160 \mathrm{~A}$ e $250 \mathrm{~A}$ correspondendo aos níveis "baixo" e "alto" respectivamente do DOE. Para a velocidade de soldagem os valores mais adequados encontrados foram de $4 \mathrm{~mm} / \mathrm{s}$ e 6,46 mm/s. Sendo assim, foram realizados 4 experimentos (4 condições de soldagem) diferentes com a repetição de pelo menos uma condição, totalizando 8 ensaios. Além disso, para que possamos, para um mesmo valor de energia, avaliar os efeitos na microestrutura das diferentes combinações entre corrente, tensão, e velocidade de soldagem, as diagonais opostas de um diagrama de interpretação dos resultados deverão ter a mesma energia de soldagem. A Tabela 2 apresenta os valores médios de corrente, tensão e velocidade de soldagem utilizados para definir os níveis alto e baixo de entrada e determinar os valores de energia de soldagem.

Tabela 2. Valores médios de corrente, tensão e velocidade de soldagem obtidos nos pré-testes e utilizados para definir os níveis alto e baixo de entrada do DOE.

Fator 1 - Corrente: (-) $160 \mathrm{~A}(+) 250 \mathrm{~A}$

Fator 2 - Velocidade de Soldagem: (-) $4 \mathrm{~mm} / \mathrm{s}(+) 6,46 \mathrm{~mm} / \mathrm{s}$

\begin{tabular}{ccccccc}
\hline Teste & Fator $\mathbf{1}$ & Fator $\mathbf{2}$ & $\begin{array}{c}\mathbf{I}_{\text {média }} \\
(\mathbf{A})\end{array}$ & $\begin{array}{c}\text { Vs } \\
(\mathbf{m m} / \mathbf{s})\end{array}$ & $\begin{array}{c}\mathbf{U}_{\text {média }} \\
(\mathbf{V})\end{array}$ & $\begin{array}{c}\text { Energia de Soldagem (kJ/mm) } \\
1\end{array}$ \\
\hline & - & - & $164 \pm 1,3$ & 4,0 & $14,73 \pm 0,60$ & $0,57 \pm 0,08$ \\
3 & - & - & $254 \pm 0,8$ & 4,0 & $15,10 \pm 0,53$ & $0,95 \pm 0,07$ \\
4 & + & + & $163 \pm 1,0$ & 6,46 & $14,60 \pm 0,80$ & $0,37 \pm 0,09$ \\
Rep 1 & - & + & $254 \pm 0,9$ & 6,46 & $15,20 \pm 0,72$ & $0,60 \pm 0,05$ \\
Rep 2 & + & - & $162 \pm 1,0$ & 4,0 & $16,30 \pm 0,93$ & $0,66 \pm 0,07$ \\
Rep 3 & - & - & $253 \pm 0,5$ & 4,0 & $16,90 \pm 1,01$ & $1,07 \pm 0,05$ \\
Rep 4 & + & + & $162 \pm 1,2$ & 6,46 & $15,01 \pm 0,90$ & $0,38 \pm 0,10$ \\
\end{tabular}

Após a formação do corpo de prova soldado foram retiradas amostras para caracterização microestrutural e avaliação da resistência à corrosão. Foram realizadas microscopia óptica, microscopia eletrônica de varredura, espectroscopia por energia dispersiva (EDS) e perfil de microdureza Vickers nos quais as amostras preparadas seguiram a técnica metalográfica padrão (lixamento, polimento e ataque). As amostras foram atacadas com Nital (3\% e 10\%) e pelo reagente Beraha modificado, composto por $20 \mathrm{~mL}$ de ácido clorídrico $(\mathrm{HCl}), 80 \mathrm{~mL}$ de água destilada, 0,3 g de metabissulfeto de potássio e 0,5 g de cloreto férrico.

Para avaliação da resistência à corrosão através de medidas eletroquímicas (polarização e impedância) foram realizados ensaios de acordo com a norma ASTM G5-94 [15]. Foram utilizados como eletrodos de trabalho os metais de base e da região soldada com área geométrica de $1 \mathrm{~cm}^{2}$ (longitudinal), um contra-eletrodo de platina e um eletrodo de referência de prata/cloreto de prata. Antes de cada ensaio, os eletrodos de trabalho ficaram imersos em uma solução de $\mathrm{NaCl} 3,5 \%$ por 1 hora para obtenção do potencial de circuito aberto (OCP). As curvas de polarização foram obtidas a partir da varredura do potencial de OCP à temperatura ambiente. A varredura iniciou-se no potencial de corrosão de cada aço, a uma taxa de $0,333 \mathrm{mVs}^{-1}\left(1,2 \mathrm{Vh}^{-1}\right)$ até atingir o potencial de pite (Epite). Os ensaios de impedância eletroquímica foram realizados numa faixa de varredura de $10 \mathrm{mHz}$ a $100 \mathrm{kHz}$ e com amplitude de perturbação de $10 \mathrm{mV}$ e taxa de aquisição de dados de 10 pontos por década. 


\section{Resultados e Discussão}

A Figura 1 mostra a representação esquemática da geometria do cordão de solda obtido pelo processo GTAW sem metal de adição que foi utilizado neste trabalho. A zona fundida abrangerá uma região de mistura formada pelos metais de base. Para os cordões obtidos a partir de uma corrente de 250 A e baixa velocidade de soldagem houve a formação do reforço de raiz, isto é, formação de um reforço na face oposta à de contato com o eletrodo que extrapola a espessura da junta soldada.

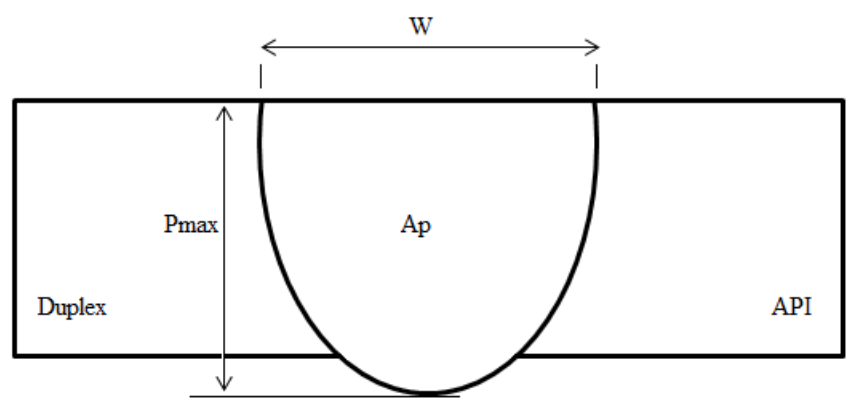

Figura 1. Representação esquemática das características geométricas do cordão. W - largura, Pmax - penetração máxima e Ap - área de penetração, Duplex - Aço Inoxidável, API - Aço de Alta resistência e baixa liga da classe API (American Petroleum Institute).

\subsection{Avaliação da geometria do cordão}

Este trabalho aborda a caracterização microestrutural e resistência à corrosão de uma junta dissimilar, porém, a fim de estudar os efeitos de uma variação dos parâmetros de soldagem e contribuir em termos de controle do processo, será feito um breve estudo sobre a geometria do cordão de solda cuja união se dá apenas pelo fornecimento de aporte térmico. Assim, variáveis fundamentais que irão influenciar na tanto na geometria unidimensional quanto bidimensional como velocidade de alimentação, tipo de consumível (diâmetro, composição química) foram descartadas nesta análise.

A Tabela 3 mostra as respostas do processo para as características geométricas do cordão para investigação operacional do efeito da corrente e velocidade na soldagem de materiais dissimilares. A resposta do processo é a consequência do conjunto de influências dos parâmetros de soldagem, variáveis internas do processo e suas possíveis interações nessa resposta. Para as análises que se seguem, são apresentados os principais efeitos dos fatores para um intervalo de confiança de $95 \%$ considerando a distribuição de student (valor tabelado de 2,776). Para todos os resultados, o fator possui uma variação de 2,776 vezes o erro padrão do efeito em si, sempre centrado na média das contribuições dos fatores, considerando seus níveis. A medida média é considerada estatisticamente significativa se o intervalo calculado, com 95\% de confiança, não contiver o valor zero.

Ainda, para interpretação dos resultados serão utilizados diagramas (Figuras 2, 3 e 4) que irão auxiliar na análise dos dados gerados. Para cada variável de saída do planejamento, foi estabelecido um diagrama para que se fosse possível entender a influência das variáveis de entrada (representadas nos eixos x e y das figuras) na resposta avaliada. Assim, foram realizados 4 experimentos (4 condições de soldagem) distintos com pelo menos uma repetição, totalizando 8 ensaios para análise das variáveis desejadas. Cada círculo do diagrama representa a média de uma resposta avaliada a partir de diferentes combinações das variáveis de entrada. As flechas indicam a variação (positiva ou negativa) de uma determinada resposta quando se trocam as variáreis de formação. Além disso, para que possamos, para um mesmo valor de energia, avaliar os efeitos na microestrutura das diferentes combinações entre corrente, tensão, e velocidade de soldagem, as diagonais opostas do diagrama de interpretação dos resultados tiveram a mesma energia de soldagem. As figuras também apresentam uma quadro que apresentam a média global dos efeitos principais das variáveis de entradas isoladas e combinados das variáveis de entrada nas respostas a serem estudadas.

Tabela 3. Respostas do processo do planejamento de experimento $2^{2}$ com repetição.

\begin{tabular}{|c|c|c|c|c|c|c|c|}
\hline \multirow[b]{2}{*}{ Teste } & \multirow[b]{2}{*}{ Fator 1} & \multirow[b]{2}{*}{ Fator 2} & \multicolumn{3}{|c|}{ Geometria do Cordão } & \multicolumn{2}{|c|}{ Microestrutura da Zona Fundida } \\
\hline & & & $\begin{array}{l}\text { Pmax } \\
\text { (mm) }\end{array}$ & $\underset{(\mathrm{mm})}{W}$ & $\underset{\left(\mathrm{mm}^{2}\right)}{\mathrm{Ap}}$ & $\begin{array}{c}\text { Ferrita } \\
\text { (\%) }\end{array}$ & $\begin{array}{l}\text { Austenita } \\
\text { (\%) }\end{array}$ \\
\hline 1 & - & - & 2,47 & 6,75 & 9,63 & 57 & 43 \\
\hline 2 & + & - & 5,10 & 8,89 & 34,14 & 92 & 8 \\
\hline 3 & - & + & 0,96 & 5,24 & 4,09 & 55 & 45 \\
\hline 4 & + & + & 3,01 & 6,67 & 13,01 & 66 & 34 \\
\hline 5 & - & - & 2,45 & 7,28 & 13,96 & 61 & 39 \\
\hline
\end{tabular}


Tabela 3. Continuação...

\begin{tabular}{|c|c|c|c|c|c|c|c|}
\hline \multirow[b]{2}{*}{ Teste } & \multirow[b]{2}{*}{ Fator 1} & \multirow[b]{2}{*}{ Fator 2} & \multicolumn{3}{|c|}{ Geometria do Cordão } & \multicolumn{2}{|c|}{ Microestrutura da Zona Fundida } \\
\hline & & & $\begin{array}{l}\text { Pmax } \\
(\mathrm{mm})\end{array}$ & $\begin{array}{c}W \\
(\mathrm{~mm})\end{array}$ & $\begin{array}{c}\mathrm{Ap} \\
\left(\mathrm{mm}^{2}\right)\end{array}$ & $\begin{array}{l}\text { Ferrita } \\
\text { (\%) }\end{array}$ & $\begin{array}{l}\text { Austenita } \\
\text { (\%) }\end{array}$ \\
\hline 6 & + & - & 5,50 & 9,67 & 35,12 & 88 & 12 \\
\hline 7 & - & + & 1,06 & 5,00 & 4,13 & 53 & 47 \\
\hline 8 & + & + & 2,20 & 5,80 & 11,90 & 70 & 30 \\
\hline
\end{tabular}

A geometria unidimensional será aqui definida como a geometria final de um cordão de solda determinada pelos valores de penetração e largura, conforme definidos na Figura 1. O diagrama para interpretação dos resultados calculados a partir do planejamento fatorial a dois níveis para a resposta penetração máxima (Figura 2) mostra que os efeitos das variáveis "corrente e velocidade de soldagem" são estatisticamente significativos (verificado pela construção dos intervalos de confiança a 95\%, apresentados entre parênteses). Examinando a figura constata-se que, elevando-se a corrente de soldagem, há aumento significativo de 2,22 $\mathrm{mm}$ da penetração. Entretanto, quando a velocidade de soldagem aumenta nota-se uma redução nos valores de penetração (em média 2,1 mm). Além disso, pelo diagrama é possível observar que não existe efeito de interação estatisticamente significativo entre corrente e velocidade de soldagem na resposta penetração máxima. Assim, como na soldagem de materiais que não são dissimilares, a diminuição do valor de penetração está relacionada ao aumento na velocidade de soldagem. Ainda, pode-se observar que, nas diagonais opostas do diagrama de interpretação de resultados, onde a energia de soldagem foi a mesma para diferentes combinações de corrente, tensão e velocidade não ocorreram alterações significativas nos valores de penetração, independente da velocidade de soldagem utilizada. Este resultado pode está relacionado ao pequeno aumento da tensão de soldagem que, juntamente com a velocidade de soldagem contribuiu para uma proximidade dos valores de penetração.

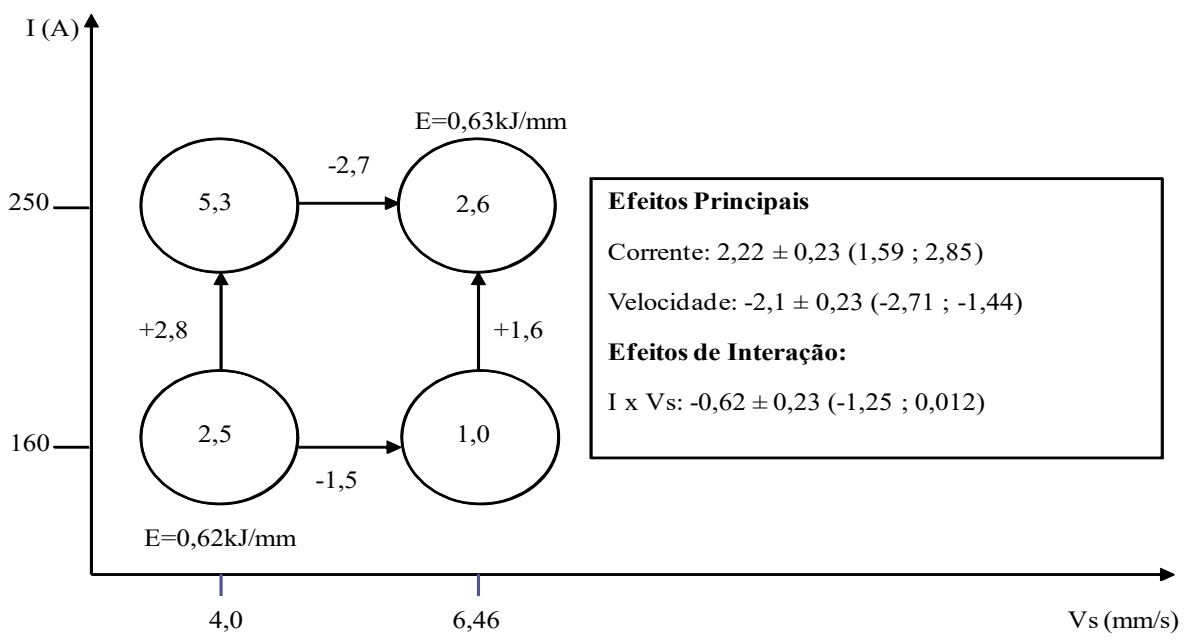

Figura 2. Diagrama para interpretação da resposta penetração (em $\mathrm{mm})$.

Os resultados da Figura 3 mostram que a largura total do cordão foi influenciada significativamente pela mudança da velocidade de soldagem e em menor escala pela corrente utilizada. Elevando-se a velocidade ocorre uma diminuição média na largura do cordão. Já para uma variação na corrente nota-se um aumento médio na largura que pode estar associado a um pequeno aumento da tensão de soldagem. Em média, um aumento na corrente de soldagem provocou um aumento na largura de $1,55 \mathrm{~mm}$. Trocando-se a velocidade de soldagem existe uma diminuição significativa da largura do cordão em $2,25 \mathrm{~mm}$. Entretanto não existe efeito de interação estatisticamente significativo entre corrente e velocidade de soldagem. Para um mesmo valore de energia de soldagem os valores obtidos para a largura são próximos. A partir dos resultados acima é valido dizer que o comportamento apresentado pala largura dos cordões de solda é semelhante aos cordões de uma soldagem convencional sendo a velocidade de soldagem e a tensão fatores determinantes na formação desta resposta. 


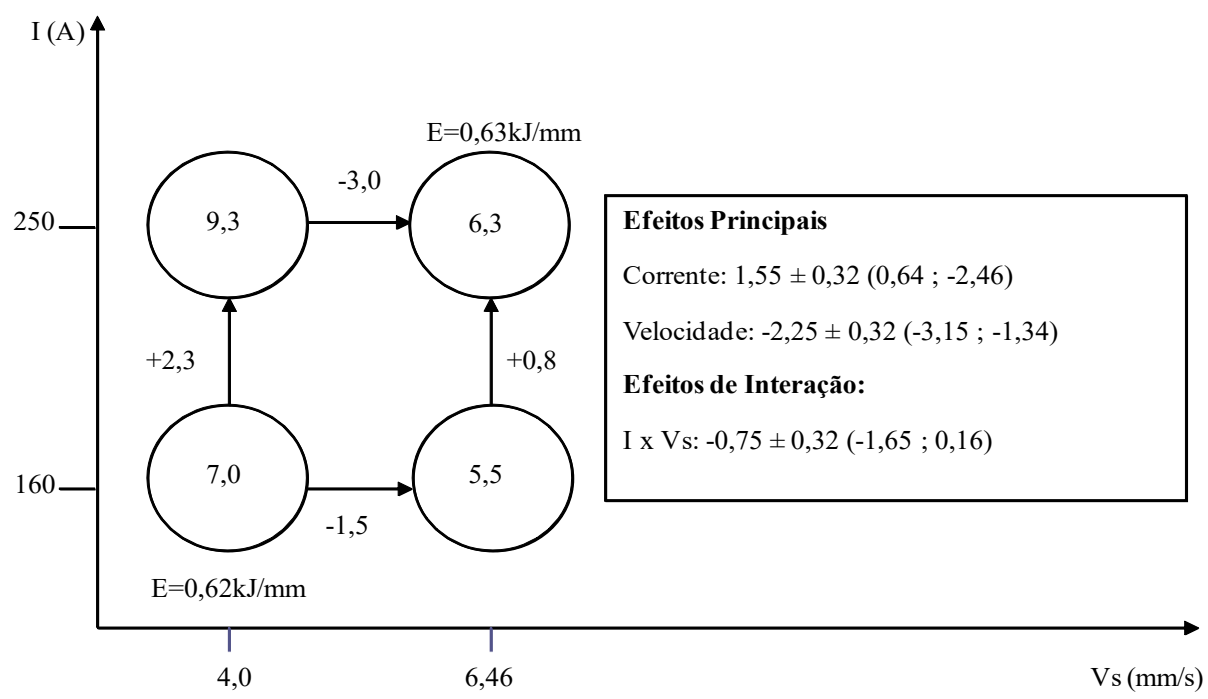

Figura 3. Diagrama para interpretação da resposta largura (em $\mathrm{mm})$.

A geometria bidimensional é aqui definida como a geometria final do cordão de solda tomando os valores da área total da zona fundida. Como a penetração foi influenciada significativamente tanto pela corrente como pela velocidade, espera-se que a área total também o seja, visto que não há uma junta a ser preenchida com metal de adição. Esta suposição é confirmada pela Figura 4, onde se observa um aumento médio de $15,55 \mathrm{~mm}^{2}$ devido ao aumento da energia de soldagem. Além disso, para um aumento de velocidade, nota-se uma redução média de $14,85 \mathrm{~mm}^{2}$. Como a penetração é diretamente proporcional a corrente, e a tensão exerce maior influência sob a largura do cordão, um aumento nessas variáveis o provocou um aumento área de penetração do cordão decorrente de um aumento na energia de soldagem, assim, pode-se dizer que a energia fornecida à peça foi fundamental para um aumento na área do cordão. Ao se variar, a velocidade, nota-se uma diminuição da energia de soldagem, e assim, uma redução de área. Além disso, existe efeito de interação estatisticamente significativo entre corrente e velocidade de soldagem, ou seja, essas variáveis quando combinadas alteram simultaneamente a geometria do cordão de solda.

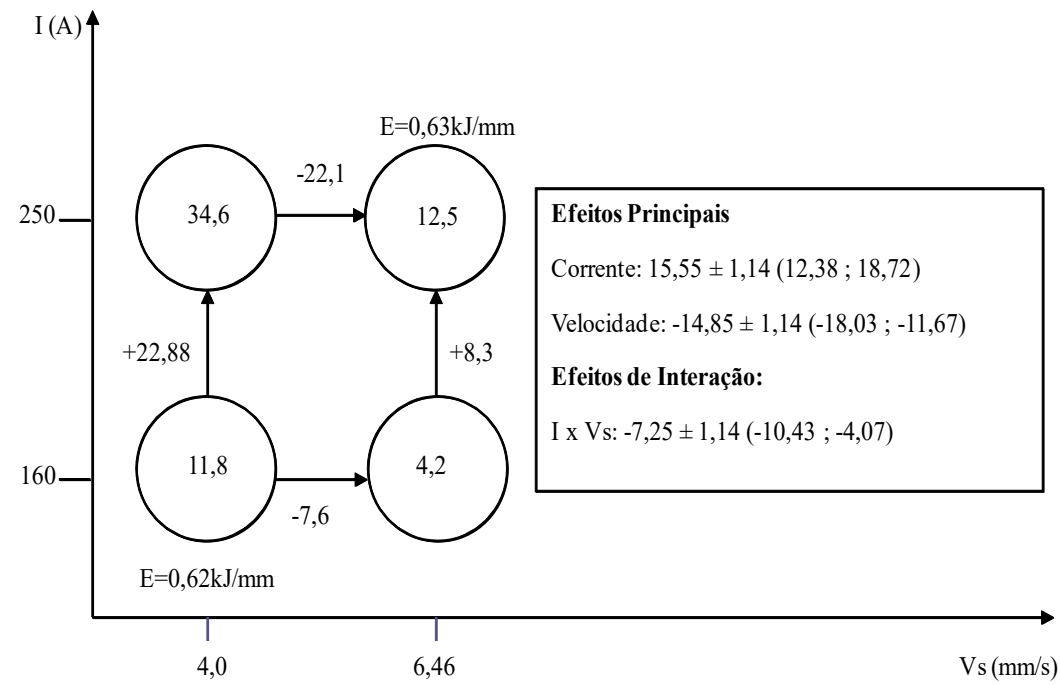

Figura 4. Diagrama para interpretação da resposta área de penetração (em $\left.\mathrm{mm}^{2}\right)$.

\subsection{Avaliação microestrutural}

Os aços de alta resistência e baixa liga da classe API 5L X80 possuem uma microestrutura constituída de bainita e colônias de ferrita poligonal de tamanhos heterogêneos e polimórficos orientados no sentido de laminação com tamanho de grão ASTM aproximadamente 15 , nos quais as máximas proporções de bainita se formam na superfície [16]. Além disso, a zona termicamente afetada (ZTA) possui uma região de grãos grosseiros próximos a zona fundida e uma região de transição de granulação fina localizada próxima ao metal de base. Foram encontrados tanto no metal de base quanto na ZTA a presença de 
microconstituintes de martensita e austenita (MA) que são encontrados dentro de colônias de bainita e nos contornos de grão de ferrita. Através da microscopia eletrônica de varredura apresentada na Figura 5, é possível observar a presença de Ferrita Poligonal (PF) e em menor número a presença de colônias de MA característicos do API. Ainda, a Figura $5 b$ também apresenta a microestrutura típica encontrada na ZTA para todas as condições de soldagem, no qual é possível observar na região de granulação grosseira a presença de Ferrita de Widmanstätten (WF) nucleada nos contornos de grão da austenita favorecida por um resfriamento lento $[15,17]$.

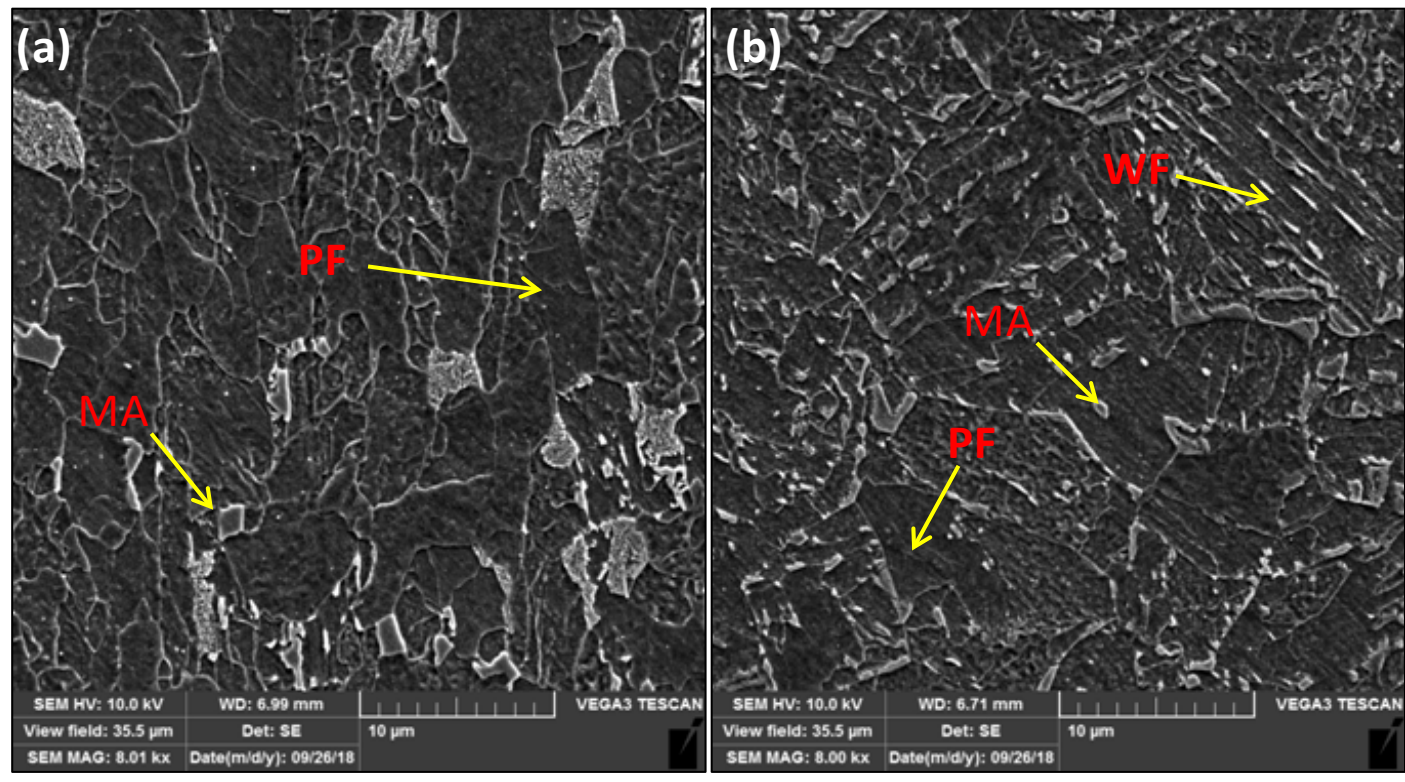

Figura 5. Microscopia eletrônica de varredura. (a) Metal base. (b) Zona termicamente afetada.

As amostras do aço duplex apresentaram uma fase austenítica com grãos apontando em uma direção preferencial resultante do processo de fabricação. Esses aços possuem uma microestrutura formada por ilhas brancas de austenita cercadas por uma matriz de ferrita cuja fração volumétrica de austenita é da ordem de 0,48 não apresentando fases secundárias. Ainda, a adição de nitrogênio neste tipo de aço, concentrando-se basicamente na austenita, conferem um aumento da tenacidade e a resistência à corrosão na zona termicamente afetada em relação ao metal de base. A Figura 6 apresenta a micrografia do metal e sua respectiva zona afetada pelo calor obtida de uma amostra do sentido transversal à superfície da chapa. Além do típico crescimento de grãos da ZTA, o ciclo térmico imposto provocou uma transformação da austenita. Foram encontradas; Austenita Alotriomórfica (AA), microestrutura formada em altas temperaturas cuja nucleação ocorre nos contornos de grãos da ferrita durante o resfriamento, Austenita de Widmanstätten (WA), nucleada nos contornos de grão da austenita alotriomórfica ou da ferrita delta cujo crescimento se dá ao longo de planos específicos e, por fim, Austenita Intragranular (IA), cujo processo de formação se dá no interior dos grãos de ferrita em baixas temperaturas na ferrítica supersaturada.

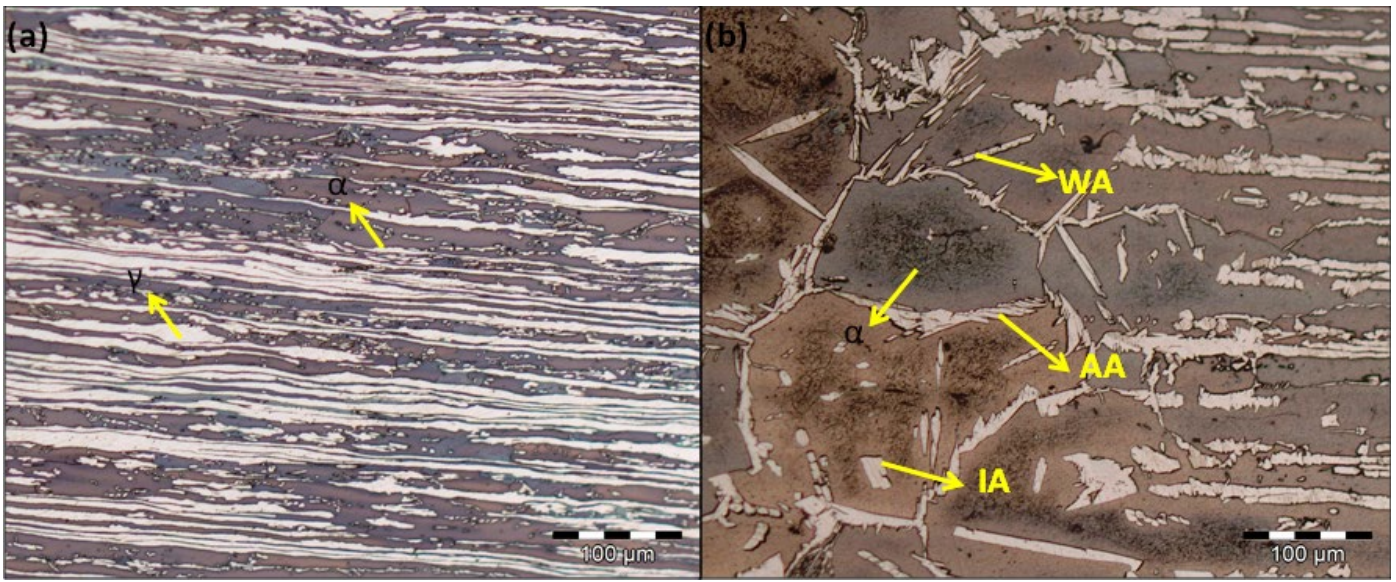

Figura 6. Aspecto Micrográfico duplex UNS S32304. (a) Metal base. (b) Zona termicamente afetada. 
A Figura 7 apresenta a microestrutura da zona fundida. A microestrutura obtida com o reagente Nital $10 \%$ é mostra a presença de grãos alongados em formato acicular e a formação de microestruturas análogas à Ferrita Primária de Contorno de Grão PF(G) e Ferrita Poligonal Intragranular PF (I). Além disso, o reagente Behara modificado mostrou que, independente da condição de soldagem, além da ferrita indicada pelo Nital 10\%, essa há a presença de austenita.

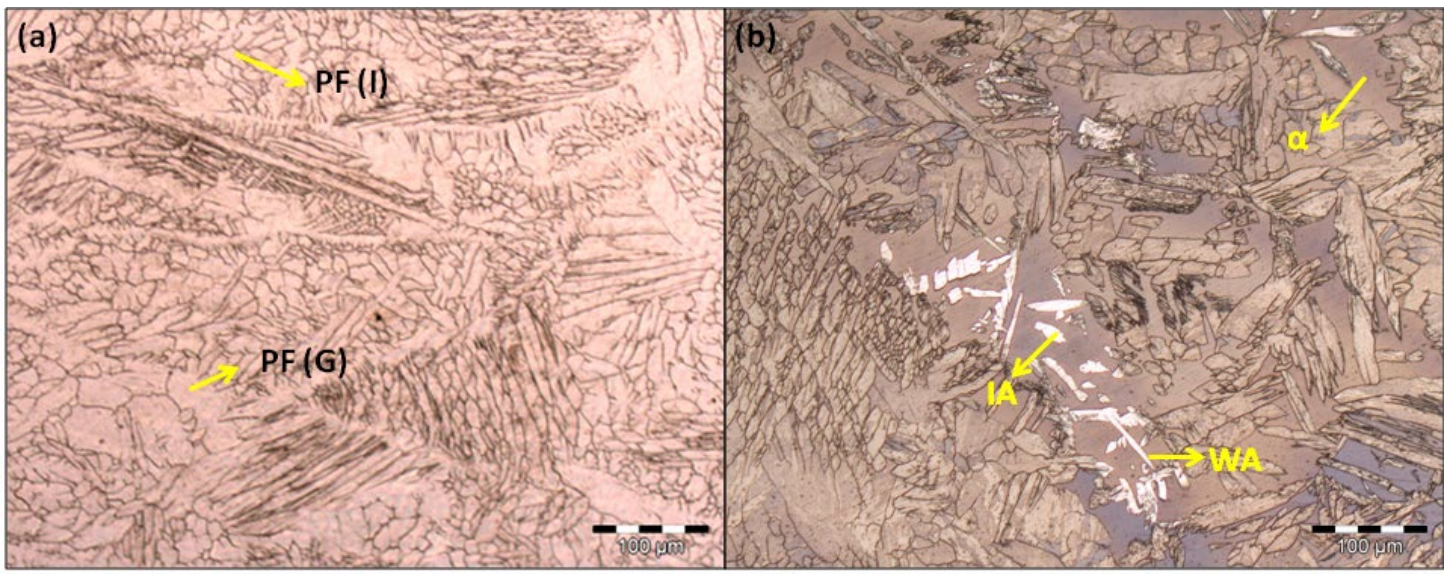

Figura 7. Aspecto Micrográfico Zona Fundida . (a) Nital 10\%. (b) Behara Modificado.

Para avaliação dos efeitos de uma variação da energia de soldagem na microestrutura da zona fundida será utilizado o planejamento fatorial do tipo $2^{2}$. Ainda, foi investigado se, para um mesmo valor de energia de soldagem os cordões de solda formados por diferentes combinações de corrente, tensão e velocidade, apresentaram uma fração volumétrica de suas microestruturas semelhantes. Assim, foi construído um diagrama para interpretação de resposta baseado na fração volumétrica de austenita obtidas via ferritoscópio da região soldada apresentado na Figura 8. A partir da figura, pode-se observar que o efeito da corrente de soldagem é estatisticamente significativo na microestrutura da zona fundida, quando há uma elevação no valor de corrente, há um aumento médio de $10,0 \%$ na fração volumétrica de austenita. Por outro lado, nota-se uma diminuição em média de $9,53 \%$ da fração volumétrica devido a um aumento na velocidade de soldagem. Em outras palavras, aumentando a energia de soldagem fornecida à poça de fusão favoreceu o surgimento da austenita. Esta observação pode estar relacionada a uma menor taxa de resfriamento devido ao aumento do aporte térmico fornecido. Por outro lado, há um efeito significantemente estatístico inerente à interação entre velocidade e corrente, sendo assim, a duas variáveis combinadas irão alterar a fração volumétrica de austenita. Além disso, nota-se que, para os ensaios realizados com uma mesma energia de soldagem, porém com diferentes combinações das variáveis de entrada, as frações volumétricas de austenita foram semelhantes, isto é, independente dos valores das variáveis de entrada, desde que a energia de soldagem seja mantida constante, não haverá alterações significativas das frações volumétricas das microestruturas da zona fundida.

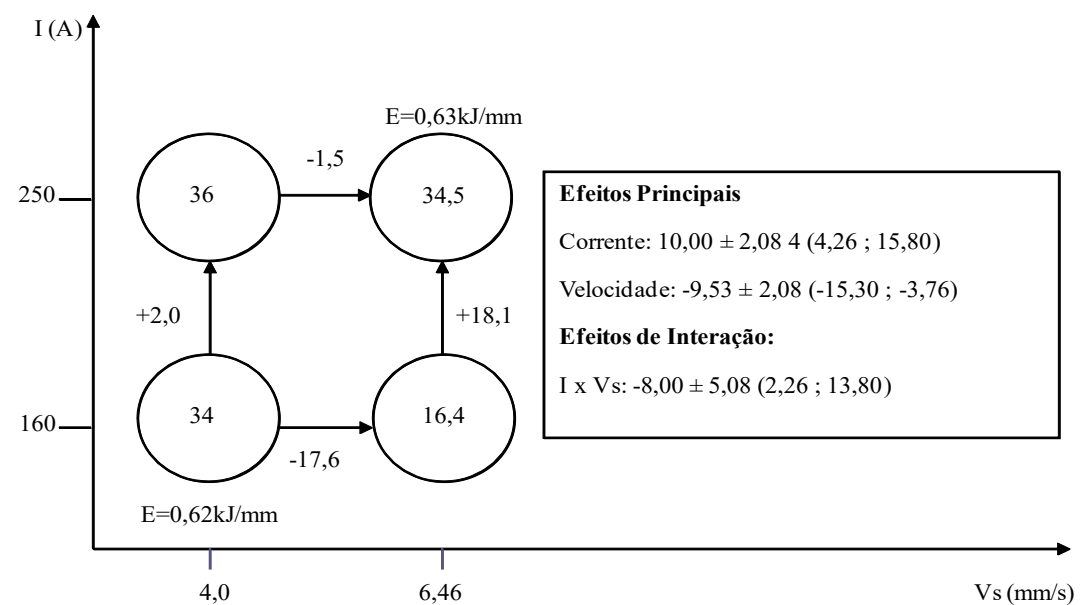

Figura 8. Diagrama para interpretação da resposta em função da fração volumétrica de Austenita (\%). 


\subsection{Perfil de microdureza}

Foi realizado um perfil de microdureza a partir da linha de fusão da zona fundida (região central da solda) até os respectivos metais de base para cada uma das condições de soldagem. As curvas apresentadas na Figura 9 correspondem aos valores médios para cada uma das condições do planejamento de experimentos. É possível observar que, na região soldada, há um aumento da dureza em ralação aos metais de base. Aumento esse que pode estar relacionado às microestruturas de formato acicular encontrados nesta região. Além disso, foram encontrados valores de microdureza da ordem de $500 \mathrm{HV}$ que sugerem o surgimento de uma microestrutura martensítica, possivelmente constituída devido à difusão de átomos de carbono do API a zona fundida [7].

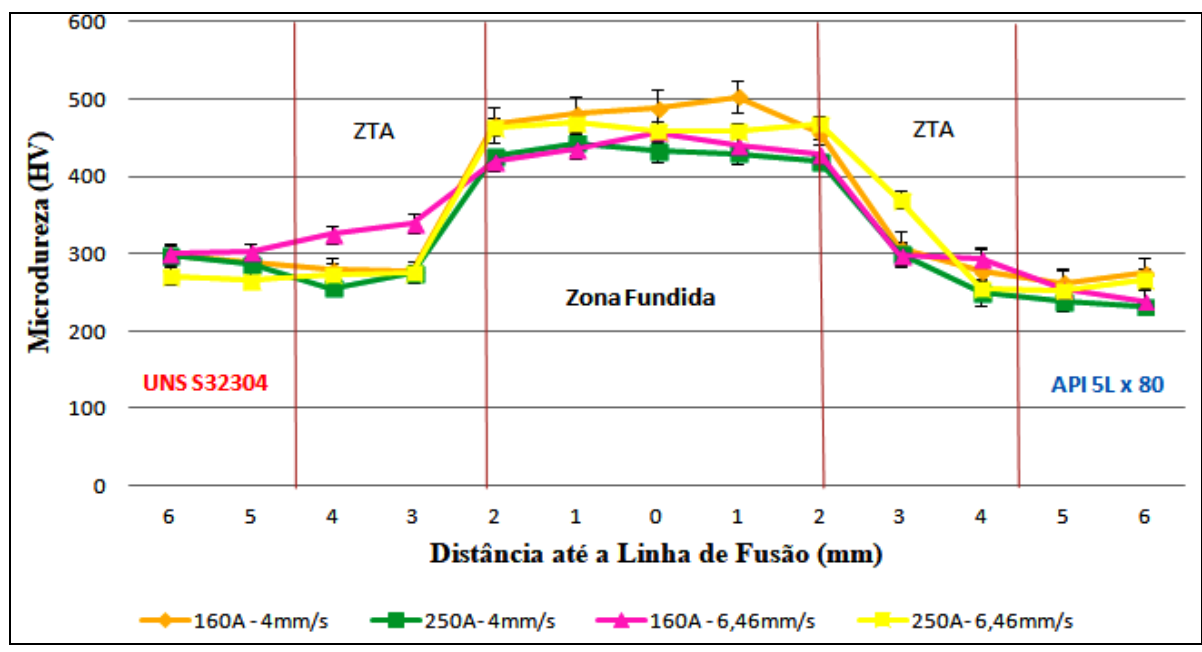

Figura 9. Perfil de microdureza (HV).

\subsection{Avaliação da resistência à corrosão}

As curvas do potencial de circuito aberto versus tempo de imersão em solução de $\mathrm{NaCl}$ 3,5\% são apresentadas na Figura 10 . A figura mostra o potencial de circuito aberto para as regiões soldadas comparadas com seus respectivos metais de base à temperatura ambiente. Pode-se observar que o potencial de saída para o duplex é de aproximadamente -0,2 V e permanece relativamente constante durante todo o ensaio caracterizando um comportamento estável. Tanto o API quanto as regiões soldadas apresentaram baixo potencial inicial de abandono quando imersos na solução e um decaimento dos valores de potencial indicando uma dificuldade na formação de filmes passivos quando em contato com a solução. Ainda, a região soldada, independentemente da energia de soldagem aplicada, apresentou um desempenho superior ao API.

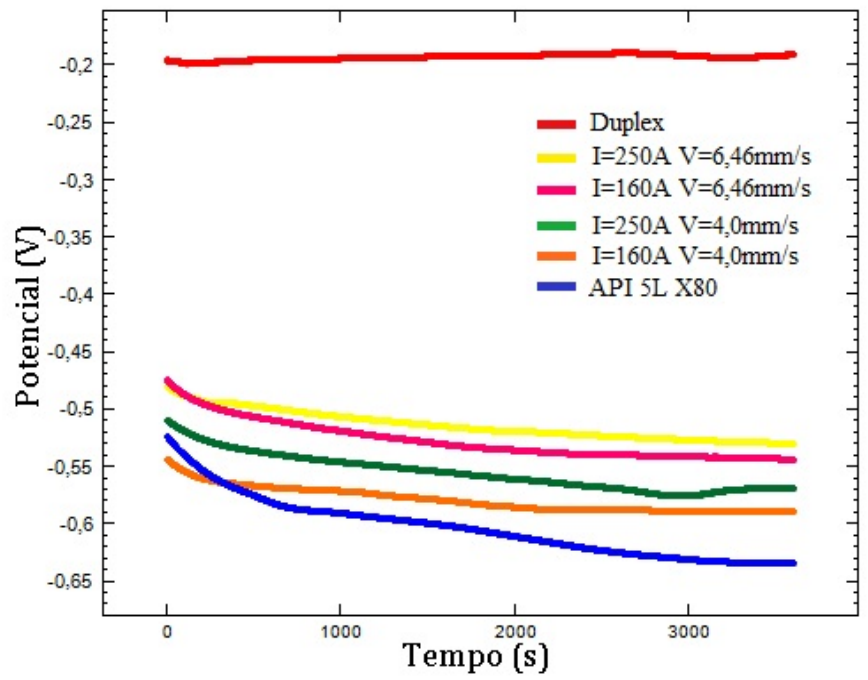

Figura 10. Variação do potencial de circuito aberto ( $\mathrm{NaCl} 3,5 \%)$. 
As curvas de polarização anódica dos eletrodos de trabalho são mostradas na Figura 11. O filme passivo do aço duplex se mostrou instável na faixa de potencial aplicado entre $-190 \mathrm{mV}$ até aproximadamente $-34 \mathrm{mV}$, fato este caracterizado por um aumento na densidade de corrente. Ainda, o filme passivo apresenta boa resistência à corrosão justificado pela pequena variação dos valores de densidade de corrente. Acima do potencial de $350 \mathrm{mV}$, ocorrem aumentos sucessivos nas densidades de corrente indicando o surgimento de pites na fase ferrítica do duplex [18]. Para todas as condições de soldagem, as curvas de polarização obtidas a partir de amostras das zonas fundidas apresentaram comportamento superior ao metal de base API. O cordão de solda formado por corrente e velocidade de soldagem nos níveis altos do planejamento de experimentos foi o que apresentou melhor resistência à corrosão seguida do cordão de solda formada por baixa corrente e alta velocidade de soldagem. As zonas fundidas formadas por baixa velocidade de soldagem ( $V=4 \mathrm{~mm} / \mathrm{s}$ ) apresentaram resistência à corrosão levemente inferior aos cordões citados anteriormente.

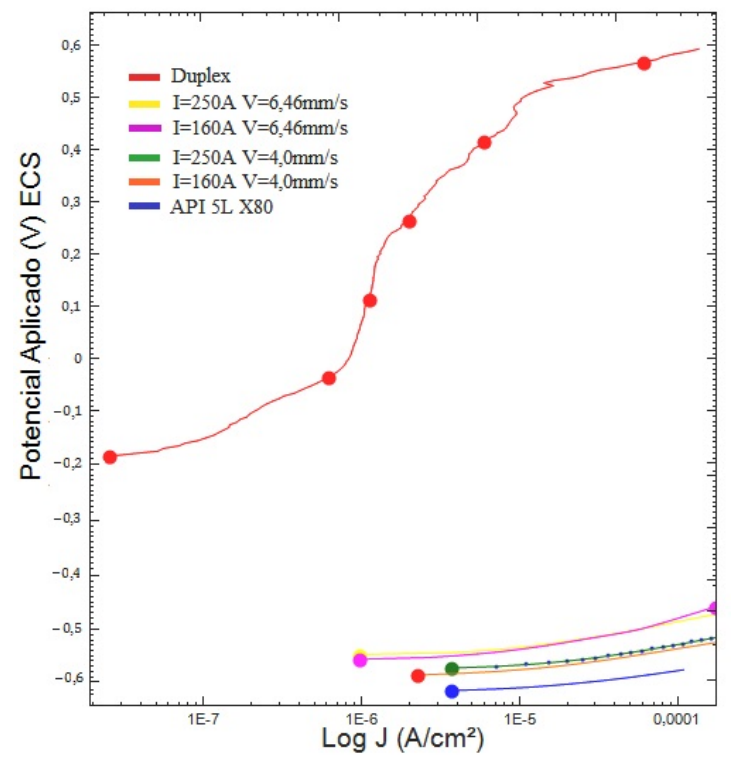

Figura 11. Curvas de Polarização anódica ( $\mathrm{NaCl} 3,5 \%)$. ECS = Eletrodo de Calomelano Saturado.

A superioridade das regiões soldadas em relação ao API pode estar relacionada à migração de cromo e níquel do duplex para a poça de fusão durante o processo de soldagem. Resultados de espectroscopia por energia dispersiva (EDS) em linha partindo do duplex até o API mostraram um gradiente de cromo e níquel à medida que se aproxima da zona fundida. Ainda, a Tabela 4 mostra a concentração média de cromo e níquel presentes nos eletrodos de trabalho obtidos a partir da EDS em área realizada na zona fundida, que pode justificar a diferença na resistência à corrosão entre os cordões de solda. Além disso, a tabela também apresenta os parâmetros eletroquímicos relativos aos ensaios de polarização e mostram os valores de domínio de passivação, indicando que, apenas o aço duplex possui a formação de filmes passivos resistentes na solução em estudo. Em relação à zona fundida, podem-se destacar os valores moderadamente superiores para os potenciais de pite (Epite) e domínios de passivação (Epite - OCP) para os testes utilizando nível alto de velocidade de soldagem $(6,46 \mathrm{~mm} / \mathrm{s})$ que apresentaram comportamentos semelhantes quanto à resistência à corrosão.

Tabela 4. Parâmetros eletroquímicos obtidos para os eletrodos de trabalho após a polarização anódica em solução $\mathrm{NaCl} 3,5 \%$.

\begin{tabular}{ccccccr}
\hline Identificação & $\mathbf{p H}$ & $\begin{array}{c}\text { OCP (mV) } \\
\text { (ECS) }\end{array}$ & $\begin{array}{c}\text { Epite (mV) } \\
\text { (ECS) }\end{array}$ & Epite - OCP (mV) & \% Cr & \%Ni \\
UNS 32304 & $7,50 \pm 0,10$ & $-193 \pm 3,0$ & $575 \pm 6,0$ & $768 \pm 1,0$ & $22,25 \pm 0,10$ & $3,8 \pm 0,12$ \\
160/V1 & $7,48 \pm 0,20$ & $-500 \pm 6,0$ & $-598 \pm 10$ & $98 \pm 0,9$ & $10,76 \pm 1,18$ & $1,51 \pm 0,12$ \\
250/V1 & $7,49 \pm 0,12$ & $-577 \pm 7,0$ & $-459 \pm 10$ & $118 \pm 5,0$ & $11,03 \pm 0,86$ & $1,63 \pm 0,25$ \\
160/V2 & $7,62 \pm 0,11$ & $-550 \pm 10$ & $-423 \pm 10$ & $127 \pm 3,0$ & $11,60 \pm 0,71$ & $1,78 \pm 0,13$ \\
250/V2 & $7,50 \pm 0,10$ & $-549 \pm 4,0$ & $-425 \pm 10$ & $124 \pm 2,0$ & $12,48 \pm 0,67$ & $1,85 \pm 0,10$ \\
API 5L X80 & $7,48 \pm 0,13$ & $-630 \pm 8,1$ & $-570 \pm 2,0$ & $60 \pm 1,0$ & $0,19 \pm 0,01$ & $0,020 \pm 0,005$ \\
\hline
\end{tabular}

ECS = Eletrodo de Calomelano Saturado. 
Os resultados dos ensaios obtidos na condição de potencial de circuito aberto (OCP) na forma de Nyquist indicados na Figura 12 mostram que o aço inoxidável duplex apresenta, conforme esperado, um comportamento capacitivo e superior aos demais eletrodos de trabalho, exibindo uma forma característica de materiais com boa resistência à corrosão. Ainda, a figura mostra os semicírculos com formas equivalentes para os aços da região soldada superiores ao API, porém, todas as condições de soldagem apresentaram baixa resistência à passagem de corrente, o que sugere menor atividade interfacial na superfície dos eletrodos de trabalho. Ainda, de acordo com a figura, tem-se que tanto os corpos de prova da região soldada quanto o API, não apresentaram resistência à corrosão para médias e altas frequências.

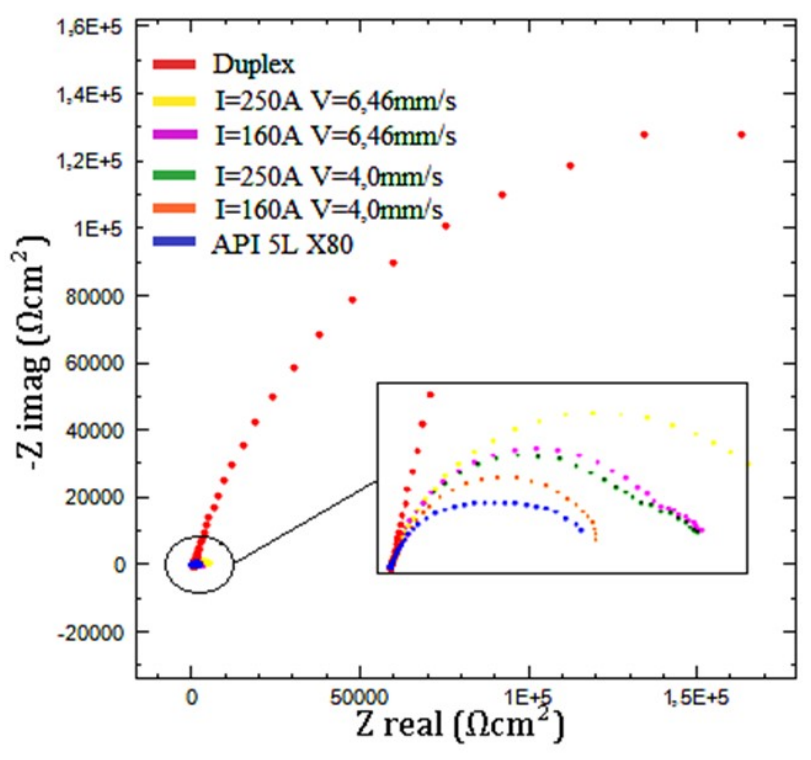

Figura 12. Diagramas de impedância eletroquímica na forma de Nyquist.

A Figura 13 apresenta os diagramas de "Bode ângulo de fase" e "Bode módulo" obtidos a partir do OCP após uma hora de imersão em solução de $\mathrm{NaCl}$ 3,5\% . O diagrama Bode ângulo para o duplex mostra que esse aço possui uma região característica de passivação entre os ângulos fase e $-65^{\circ}$ e $-75^{\circ}$ característicos de aços com resistência à corrosão. Por outro lado, a curva obtida para o API se mostra inferior as demais característico de materiais que não apresentam resistência à corrosão na solução de trabalho. Ainda de acordo com a figura, comparando a curvas relativas ao desempenho quanto a resistência à corrosão dos corpos de prova das regiões, verifica-se que para baixas e médias frequências que o cordão de solda formado por corrente e velocidade de soldagem nos níveis altos do planejamento de experimentos foi a que apresentou o melhor desempenho, entre os ângulos $-70^{\circ}$ a $-78^{\circ}$ apresentou intervalos de frequência entre 5 e $100 \mathrm{~Hz}$. Além disso, através das curvas de Bode módulo, verifica-se que os corpos de prova da região soldada não apresentam resistência à passagem de corrente para nenhum intervalo de corrente. Contudo, o aço duplex apresenta um aumento de impedância real nos intervalos de médias a baixa frequência apresentando características de material que oferece resistência à passagem de corrente elétrica. Assim, podemos dizer que, com exceção do aço inoxidável duplex, nenhum dos outros eletrodos de trabalho apresentou regiões características de formação de filmes passivos, no entanto, todos os materiais da região soldada apresentaram uma superioridade quanto à resistência à corrosão em relação ao API. 


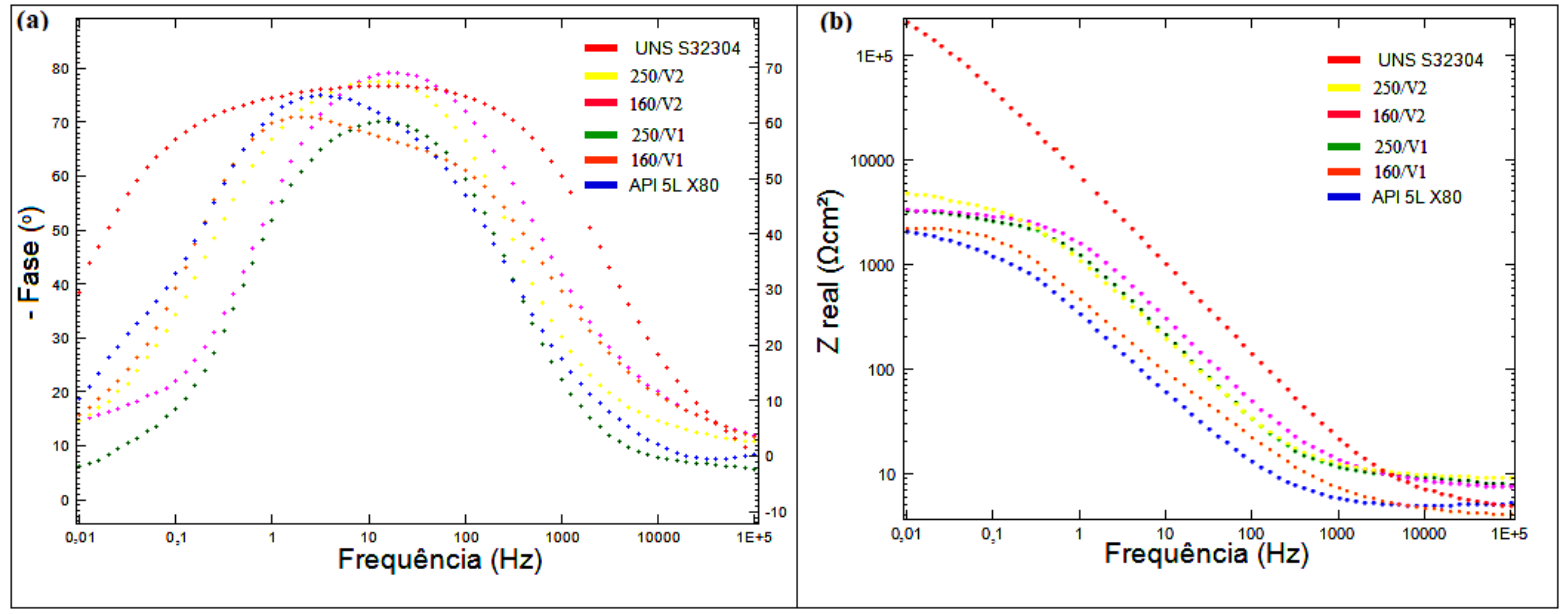

Figura 13. Curvas de Impedância eletroquímica. (a) Bode Ângulo de Fase; (b) Bode Módulo.

\section{Conclusões}

Neste trabalho, a microestrutura e as propriedades quanto à resistência à corrosão de uma junta dissimilar entre o aço inoxidável duplex UNS S32304 e um aço alta resistência e baixa liga da classe API 5L X80 unidos pelo processo GTAW autógeno foram investigadas. Com base nos resultados alcançados neste estudo, as seguintes conclusões foram obtidas:

Foram encontradas três morfologias diferentes de austenita na zona termicamente afetada do aço inoxidável (intragranular, Widmanstätten e alotriomórfica). Ainda, além da microestrutura característica do metal de base, foram encontradas na ZTA do API $5 \mathrm{~L}$ X80 ferrita de Widmanstätten para todas as condições de soldagem.

A microestrutura na zona fundida para todas as condições de soldagem apresentou uma microestrutura austenítica em uma matriz de ferrita primária. Além disso, resultados de microdureza nessa região apontaram valores elevadas em determinadas fases que sugerem a presença de uma microestrutura martensítica ou até mesmo a formação de carbonetos.

Os resultados obtidos via planejamento de experimentos mostraram que os efeitos das variáveis corrente e velocidade de soldagem são estatisticamente significativos para as respostas penetração, largura e área de penetração, porém não existe efeito de interação estatisticamente significativo entre corrente e velocidade. Sendo assim, os resultados indicaram que a geometria cordão de solda formado por materiais dissimilares foi semelhante ao encontrado na literatura para a soldagem convencional.

Os resultados também mostraram que, desde que o aporte térmico fornecido seja o mesmo, combinações diferentes de corrente, tensão e velocidade não influenciaram significativamente os resultados de fração volumétrica dos microconstituintes deste trabalho.

A zona fundida para todas as condições de soldagem se mostrou mais resistente à corrosão do que o API. Ainda, os resultados de impedância eletroquímica mostraram que, com exceção do duplex, nenhum outro eletrodo de trabalho apresentou estabilidade na formação de filmes passivos com características capacitivas. Diante disso, podemos concluir que as propriedades das juntas dissimilares utilizadas neste trabalho são compatíveis com as aplicações, sendo possível sua utilização usufruindo-se das vantagens da soldagem dissimilar.

\section{Agradecimentos}

Os autores agradecem a CAPES e ao CNPq pelo parcial apoio financeiro ao projeto.

\section{Referências}

[1] Wang J, Lu M-X, Zhang L, Chang W, Xu Li-N, Hu Li-H. Effect of welding process on the microstructure and properties of dissimilar weld joints between low alloy steel and duplex stainless steel International. Journal of Minerals, Metallurgy, and Materials. 2012;19(6):518524. http://dx.doi.org/10.1007/s12613-012-0589-z.

[2] Belkessa B, Miroud D, Ouali N, Cheniti B. Microstructure and mechanical behavior in dissimilar SAF 2205/API X52 Welded Pipes. Acta Metallurgica Sinica (English Letters). 2016;29(7):674-682.

[3] Javadi Y, Afzali O, Raeisi MH, Najafabadi MA. Nondestructive evaluation of welding residual stresses in dissimilar welded pipes. Journal of Nondestructive Evaluation. 2013;32(2):177-188. http://dx.doi.org/10.1007/s10921-013-0171-2.

[4] Joseph A, Rai SK, Jayakumara T, Muruganc N. Evaluation of residual stresses in dissimilar weld joints. International Journal of Pressure Vessels and Piping. 2005;37(3):700-705. https://doi.org/10.1016/j.ijpvp.2005.03.006. 
[5] Wang S, Ma Q, Li Y. Characterization of microstructure, mechanical properties and corrosion resistance of dissimilar welded joint between 2205 duplex stainless steel and 16MnR. Materials \& Design. 2011;32(2):831-837. https://doi.org/10.1016/j.matdes.2010.07.012.

[6] Mendonza BI, Maldonado ZC, Albiter HA, Robles PE. Dissimilar welding of superduplex stainless steel/HSLA steel for offshore applications joined by GTAW. Engineering. 2010;2:520-528. http://dx.doi.org/10.4236/eng.2010.27069.

[7] Tasalloti H, Kah P, Martikainen J. Effect of heat input on dissimilar welds of ultra high strength steel and duplex stainless steel: microstructural and compositional analysis. Materials Characterization. 2017;123:29-41. http://dx.doi.org/10.1016/j.matchar.2016.11.014.

[8] Mortazavi E, Najafabadi RA, Meysami A. Effect of heat input on microstructure and mechanical properties of dissimilar joints of AISI 316L steel and API X70 high-strength low-alloy steel. Journal of Iron and Steel Research, China. 2017;24(12):1248-1253. http://dx.doi.org/10.1016/S1006-706X(18)30024-4.

[9] Vashishtha H, Taiwade RV, Sharma S, Patil AP. Effect of welding processes on microstructural and mechanical properties of dissimilar weldments between conventional austenitic and high nitrogen austenitic stainless steels. Journal of Manufacturing Processes. 2017;25:49-59. http://dx.doi.org/10.1016/j.jmapro.2016.10.008.

[10] Devendranath Ramkumar K, Singh A, Raghuvanshi S, Bajpai A, Solanki T, Arivarasu M, et al. Metallurgical and mechanical characterization of dissimilar welds of austenitic stainless steel and super-duplex stainless steel - a comparative study. Journal of Manufacturing Processes. 2015;19:212-232. http://dx.doi.org/10.1016/j.jmapro.2015.04.005.

[11] Moteshakker A, Danaee I, Moeinifar S, Ashrafi A. Hardness and tensile properties of dissimilar welds joints between SAF 2205 and AISI 316L. Science and Technology of Welding and Joining. 2016;21(1):1-10. http://dx.doi.org/10.1179/1362171815Y.0000000062.

[12] Amer AE, Koo MY, Lee KH, Kim SH, Hong SH. Effect of welding heat input on microstructure and mechanical properties of simulated HAZ in Cu containing microalloyed steel. Journal of Materials Science. 2010;21(5):1248-1254. http://dx.doi.org/10.1007/s10853-009-4074-7.

[13] Alipooramirabad H, Ghomashchi R, Paradowska A, Reid M. Residual stress- microstructure- mechanical property interrelationships in multipass HSLA steel welds. Journal of Materials Processing Technology. 2016;231:456-467. http://dx.doi.org/10.1016/j.jmatprotec.2016.01.020.

[14] Kumar, S., Shahi, A. S. Effect of heat input on the microstructure and mechanical properties of gas tungsten arc welded AISI 304 stainless steel joints. Materials \& Design. 2011;32(6):3617-3623. https://doi.org/10.1016/j.matdes.2011.02.017.

[15] Eroglu M, Aksoy M. Effect of initial grain size on microstructure and toughness of intercritical heat affected zone of a low carbon Steel. Materials Science \& Engineering: A. 2000;286:289-297. https://doi.org/10.1016/S0921-5093(00)00801-7.

[16] Moojen RG. Soldagem de um aço API 5L-X80 com diferentes taxas de resfriamento [dissertação de mestrado]. Porto Alegre: Programa de Pós-graduação em Engenharia de Minas, Metalúrgica e de Materiais, Universidade Federal do Rio Grande do Sul; 2015.

[17] Ramirez MG, Gorni AA, Landgraf F, Ogata PH, Goldenstein H. Caracterização microestrutural de um aço API 5L-X80 através de microdureza e microscopia ótica e eletrônica. In: Associação Brasileira de Metalurgia, Materiais e Mineração. Anais do 62을 Congresso Anual da ABM; 2007; Vitória. São Paulo: ABM; 2007. 12 p.

[18] Pereira V, Sabará EWF, Caldeira L, Oliveira JR, Bueno AHS. Avaliação eletroquímica da resistência à corrosão por pites em aços inoxidáveis duplex e super duplex em soluções simuladoras de água do mar. Revista Virtual de Química. 2017; 9(6):2442-2463. http://dx.doi.org/10.21577/1984-6835.20170146. 